\title{
NHCs and Visible Light Co-catalyzed 1,4-Sulfonylacylation of 1,3-Enynes for Tetrasubstituted Allenyl Ketones
}

Lihong Wang, ${ }^{[a]}$ Ruiyang Ma, ${ }^{[a]}$ Jiaqiong Sun, ${ }^{[b]}$ Guangfan Zheng ${ }^{\star}\left[{ }^{[a]}\right.$ and Qian Zhang ${ }^{*,[a, c]}$

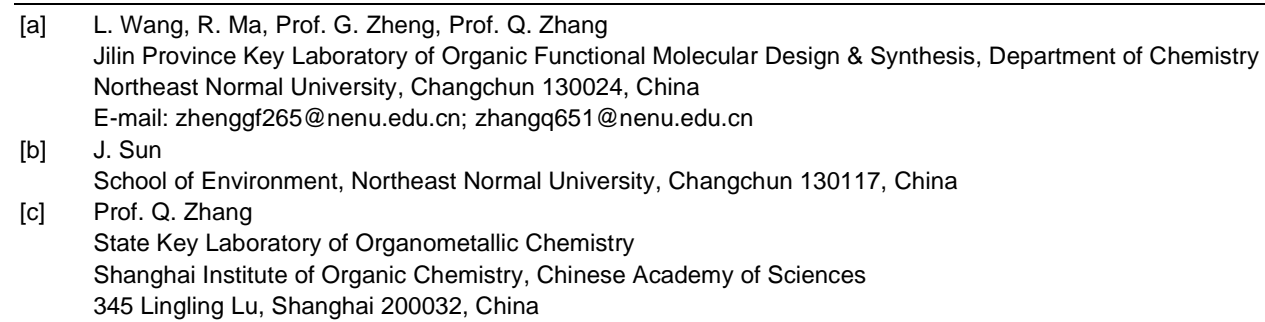

Abstract: The modulation of selectivity of highly reactive carbon radical crosscoupling for the construction of $\mathrm{C}-\mathrm{C}$ bonds represents a challenging task in organic chemistry. N-Heterocyclic carbenes (NHCs) catalyzed radical transformations opened a new avenue for acyl radical cross-coupling chemistry. With this method, highly selective cross-coupling of acyl radical with alkyl radical for efficient construction of C-C bonds were succussfully realized. However, the cross-coupling reaction of acyl radical with vinyl radicals represents an uncharted domain. We herein describe NHCs and photocatalysis co-catalyzed radical 1,4-sulfonylacylation of 1,3-enynes, providing structurally diversified valuable tetrasubstituted allenyl ketones. Mechanistic studies indicated that ketyl radicals are formed from aroyl fluorides via oxidative quenching process of excited photocatalysis, allenyl radicals are generated from chemo specific sulfonyl radical addition to the 1,3-enynes, finally, unprecedented key allenyl and ketyl radical cross-coupling provides tetrasubstituted allenyl ketones. 
Radical cross-coupling between two carbon radicals emerged as a powerful platform for constructing $\mathrm{C}-\mathrm{C}$ bonds and received increasing attention. ${ }^{1}$ Since the radical-radical coupling reactions proceeded via a diffusion-controlled manner, selectivity modulation is the critical challenge. ${ }^{1 \mathrm{~b}}$ Via radial addition to unsaturated bond to form $\mathrm{C}-\mathrm{C}$ bond, acyl radicals have been utilized in preparing diverse carbonyl compounds. ${ }^{2}$ However, radical-coupling reaction between acyl and other carbon-centered radicals is rare. $\mathrm{N}$ Heterocyclic carbenes catalysis (NHCs) has emerged as an attractive strategy in synthetic chemistry to access value-added organics via the formation of key Breslow intermediate (BI). ${ }^{3}$ Recently, the single-electron-transfer (SET) of BI was found to provide ketyl-type radical species, which opens a new avenue for acyl radical chemistry. ${ }^{4-12}$ As a result, NHCs catalyzed radical-couplings have attracted great attention after the pioneer work of Ohmiya in 2019. ${ }^{7 a}$ Alkyl radical sources such as redox-active esters, ${ }^{7}$ Katritzky pyridinium salts, ${ }^{8}$ Hantzsch ester, ${ }^{9}$ benzylic C-H bonds, ${ }^{6 \mathrm{e}}$ alkylborates, ${ }^{10 \mathrm{~g}}$ olefins ${ }^{6 \mathrm{c}, 10}$ as well as cyclopropanes ${ }^{6 \mathrm{f}}$ could be used to perform cross-coupling reaction with acyl radicals to form $\mathrm{C}-\mathrm{C}$ bond (Fig. 1a). However, to the best of our knowledge, radical-coupling reaction between vinyl radical and acyl radical has never been reported.

On the other hand, radical 1,4-difunctionalization ${ }^{13-14}$ of 1,3-enynes provides an elegant and versatile strategy for tetrasubstituted allenes from easily available feedstocks. In this regard, in situ generated allene radicals undergo cyanation, ${ }^{14 a-d}$ arylation, ${ }^{14 \mathrm{e}-\mathrm{h}}$ halogenation, ${ }^{14 \mathrm{i}}$ alkynylation, ${ }^{14 \mathrm{j}}$ trifluoromethylation, ${ }^{14 \mathrm{k}}$ or intramolecular cyclization ${ }^{141}$ to afford functionalized allenes. Radical acylation of 1,3enynes may provide straightforward access to value-added allenyl ketone units, which are crucial core in important nature products ${ }^{15}$ and synthetic intermediates. ${ }^{16}$ Recently, Studer et al. developed acylative difunctionalization of olefins ${ }^{6 c} /$ cyclopropanes $^{6 \mathrm{f}}$ and formal alkenyl ${ }^{6 \mathrm{~d}} /$ benzylic $^{6 \mathrm{e}} \mathrm{C}-\mathrm{H}$ acylation by employing aroyl fluorides as ketyl-type radical precursors. Inspired by those elegant approaches, we speculated that NHCs and visible light co-catalyzed system ${ }^{6 \mathrm{c}-6 \mathrm{f}, 9,11-12}$ enable generation of allenyl radicals and NHCs stabilized ketyl radicals under extremely mild conditions, which may offer an 
opportunity for radical acylation of 1,3-enynes. As our continuous interests in radical chemistry, ${ }^{17}$ we now describe the development of NHCs and photocatalysis cocatalyzed three-component radical 1,4-sulfonylacylation of 1,3-enynes, providing direct access to structurally diversified tetrasubstituted allenyl ketones (Fig. 1b).

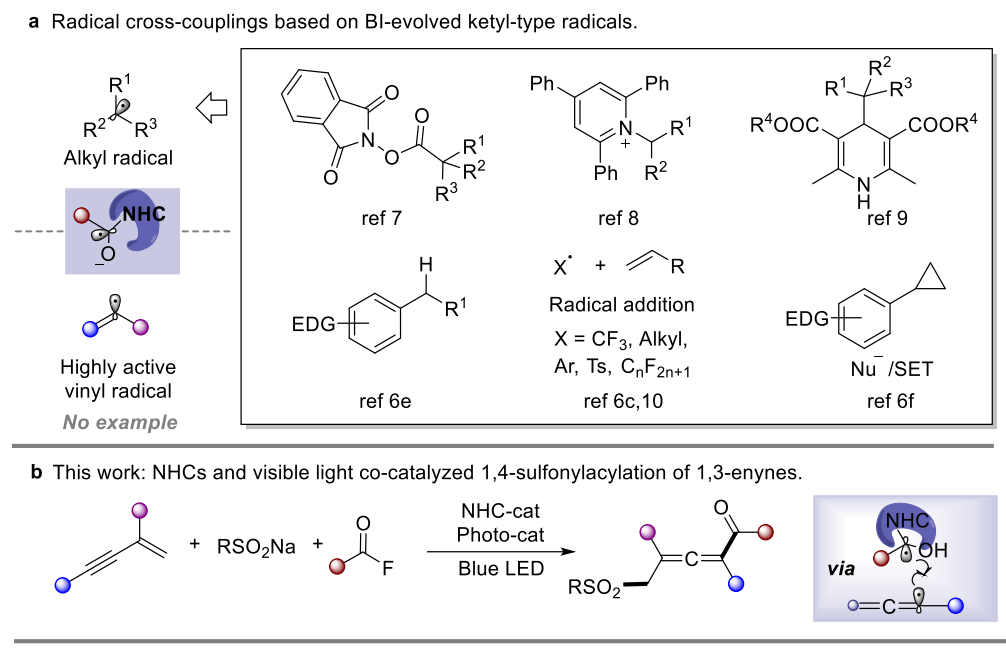

Fig. 1 Radical C-C bond formations based on BI-evolved ketyl-type radicals. a Radical crosscouplings based on BI-evolved ketyl-type radicals. b NHCs and visible light co-catalyzed 1,4sulfonylacylation of 1,3-enynes. NHC N-heterocyclic carbene, LED light-emitting diode.

\section{Results and discussion}

Reaction conditions development. We commenced our investigation by employing 1,3-enyne (1a), benzoyl fluoride (2a), $\mathrm{TolSO}_{2} \mathrm{Na}(\mathbf{3 a})$ as the prototype substrates and PC-1 (1.5 mol \%), NHC-1 (15 mol \%) as catalysts. Pleasingly, in dichloromethane (DCM) under irradiation with Blue LED at room temperature for $4 \mathrm{~h}$, the expected allenyl ketones 4 was obtained in 10\% yield combination with competitive by-product 5 (Fig. 2, entry 1). Ir-based photocatalysis PC-2 and PC-3 improved reactivity and selectivity (entries 2 and 3), while PC-4 and PC-5 were inefficient for this reaction (entries 4 and 5). The employment of other solvents such as $\mathrm{CH}_{3} \mathrm{CN}, \mathrm{PhCF}_{3}$, or THF provided 4 in relatively lower yields (entries 6-8). The structure of NHCs was crucial for chemo-selectivity control (entries 9-13). The NHC-2 and NHC-3 were unsatisfactory (entries 9 and 10). The $N$-2,6-diethyl phenyl substituted catalyst NHC-4 afforded 4 with a slightly diminished yield compared to NHC-1 (entry 11). For NHC- 
5 or NHC-6, decreased yield was observed (entries 12-13). To our delight, yield could be further improved upon running the reaction at lower concentration (entries 14-15), and affording 4 in $80 \%$ isolated yield with negligible 5 in $4 \mathrm{~mL} \mathrm{DCM} \mathrm{(entry} \mathrm{15).} \mathrm{The}$ desired 1,4-sulfonylacylation product was isolated in $75 \%$ yield when the reaction was run at $0.2 \mathrm{mmol}$ scale (entry 16), and these conditions were thus defined as the standard reaction conditions for subsequent investigations.

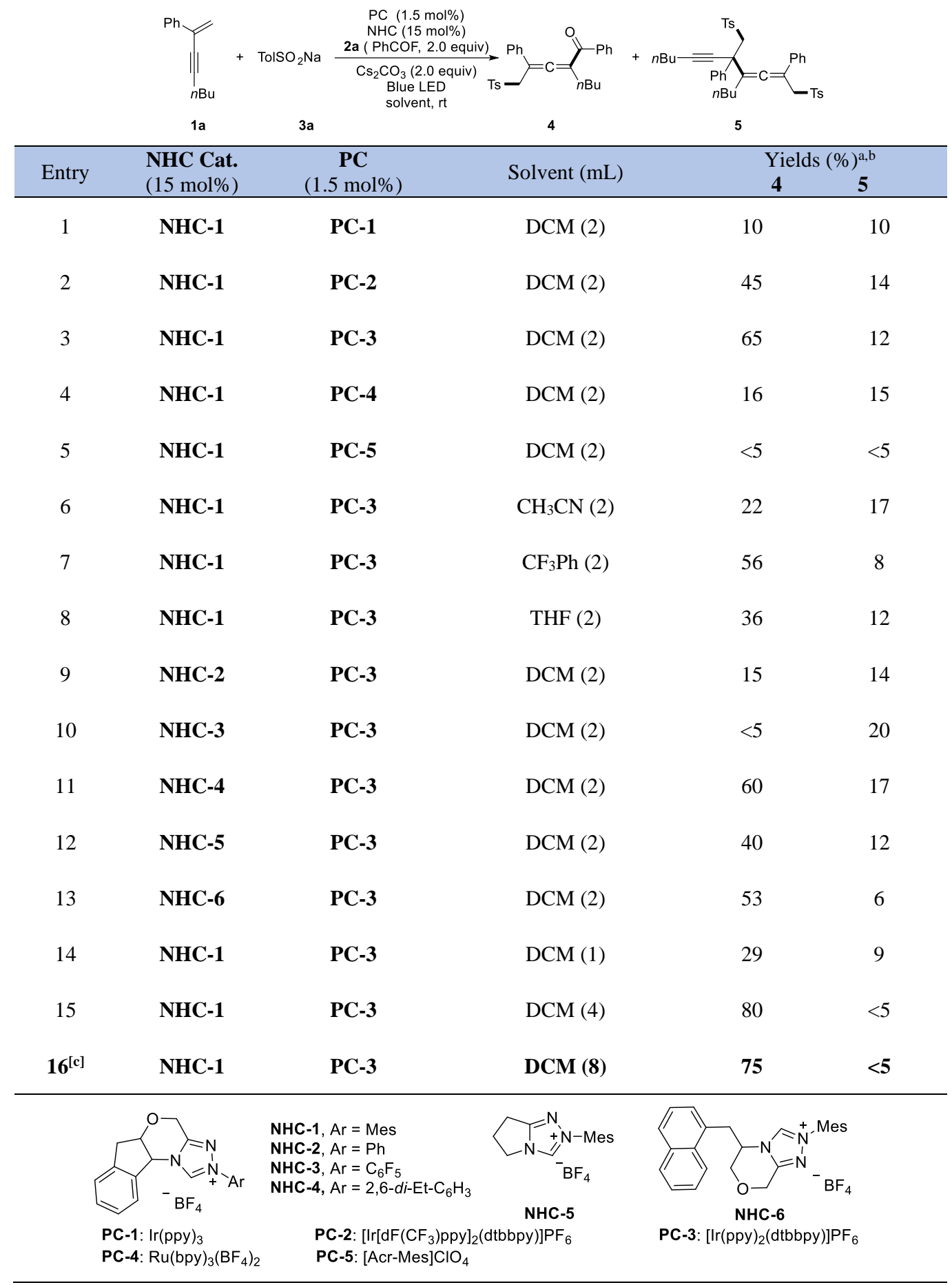




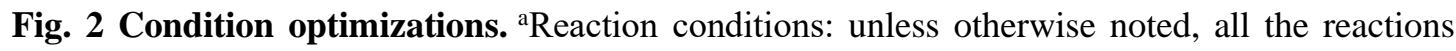
were carried out with $\mathbf{1 a}(0.1 \mathrm{mmol}), \mathbf{2 a}(0.2 \mathrm{mmol}), \mathbf{3 a}(0.2 \mathrm{mmol}), \mathbf{N H C}(0.015 \mathrm{mmol}), \mathrm{Cs}_{2} \mathrm{CO}_{3}$ (0.2 mmol), and PC (0.0015 mmol) in anhydrous solvent, irradiation with Blue LED at room

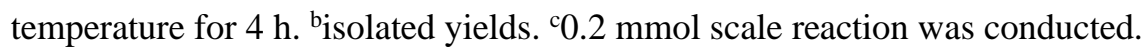

Substrate scope. With the optimized reaction conditions, the scope concerning 1,3enynes was explored. As shown in Fig 3a, 1,3-enynes bearing various electron-donating or -withdrawing substituents at ortho (6-9), meta $(\mathbf{1 0}, \mathbf{1 1})$, or para (12-16) positions of the 2-phenyl rings, such as (alkyl, methoxyl, halo, methoxycarbonyl, trifluoromethyl, and trifluoromethoxy), were fully tolerated affording the corresponding products 6-16 smoothly. 1,3-Enynes bearing naphthalene, fluorene, and pyridine were also compatible with the transformation, and corresponding products 17-19 were formed in $50-93 \%$ yields. The functional groups linked to the alkyne triple bond could also be diversified. As shown in Fig 3a, 1,3-enynes with $n$-hexyl (4-21), cyclohexyl (25), cyclopropyl (27), chloroalkyl (26) were tolerated for this transformation. Moreover, good coupling efficiencies were maintained for 2,4-diaryl substituted 1,3-enynes (23, 24). It should be noted that the vulnerable Bpin (24), insular alkyne (20), and olefin (21) units have been preserved after transformation. Furthermore, internal 1,3-enynes and 2-alkyl substituted 1,3-enynes were applicable, affording 22 and 28 in 66\% (3:1 dr.) and $71 \%$ yields, respectively. The structure of $\mathbf{2 8}$ was confirmed by X-ray singlecrystal diffraction (CCDC 2090996). ${ }^{18}$ Next, we turned our attention to the scope of the sulfonyl radical source, various $\beta$ - sulfonated allenyl ketones $\mathbf{2 9 - 4 0}$ could be obtained in good yields (Fig 3b). Sodium arylsulfinates with methyl substituents in ortho- and meta-position were compatible well under the reaction conditions, delivering $\mathbf{3 0 , 3 1}$ in 80 and $86 \%$ yields, respectively. The functional group tolerances and electronic effects were next investigated base on para-substituted sodium arylsulfinates. An array of electron-donating ( $t$-Bu), -withdrawing (cyano, trifluoromethyl, carbonyl), and halogen groups were tolerated under the standard conditions, affording 32-36 in 72-90\% yields. Sodium arylsulfinates containing naphthalene (37), pyridine (38), thiophene (39) 
proved to be viable substrates. Notably, sodium methylsulfite could deliver a difunctionalization product $\mathbf{4 0}$ in $80 \%$ yield. These exciting results encouraged us to evaluate the scope of acyl fluoride (Fig 3c). This sulfonylacylation reaction was insensitive to the steric hindrance of benzoyl fluoride (41-49). The electron-donating aryl acyl fluorides showed excellent reactivities $(\mathbf{4 1}, \mathbf{4 3 - 4 5})$, while the presence of strong electron-deficient groups (51) led to low efficiency. Remarkably, the iodine group, which is sensitive in most metal-catalyzed coupling reactions, did not inhibit the reaction $(42,47)$, providing an opportunity for further transformations. The aryl groups have been extended to naphthalene and heterocycles, providing 48 and 49 in acceptable yields. Importantly, Alkyl acyl fluoride could be used as well in this transformation, affording the corresponding allene $\mathbf{5 0}$ in $42 \%$ yield. Unfortunately, cinnamoyl fluoride (52) was not suitable for this conversion. Taking advantage of the mild reaction conditions as well as broad functional group tolerances, the 1,4-sulfonylacylation of enynes could be applied at a late-stage functionalization. As shown in Fig 3d, the 1,3enynes derived from cholesterol could participate in this reaction, delivering $\mathbf{5 3}$ in $58 \%$ (1:1 dr.) yield. Furthermore, the fluorides derived from natural products such as telmisartan and mefenamic acid were successfully converted into $\mathbf{5 4}$ and $\mathbf{5 5}$ in $85 \%$ and $61 \%$ yields, respectively. 


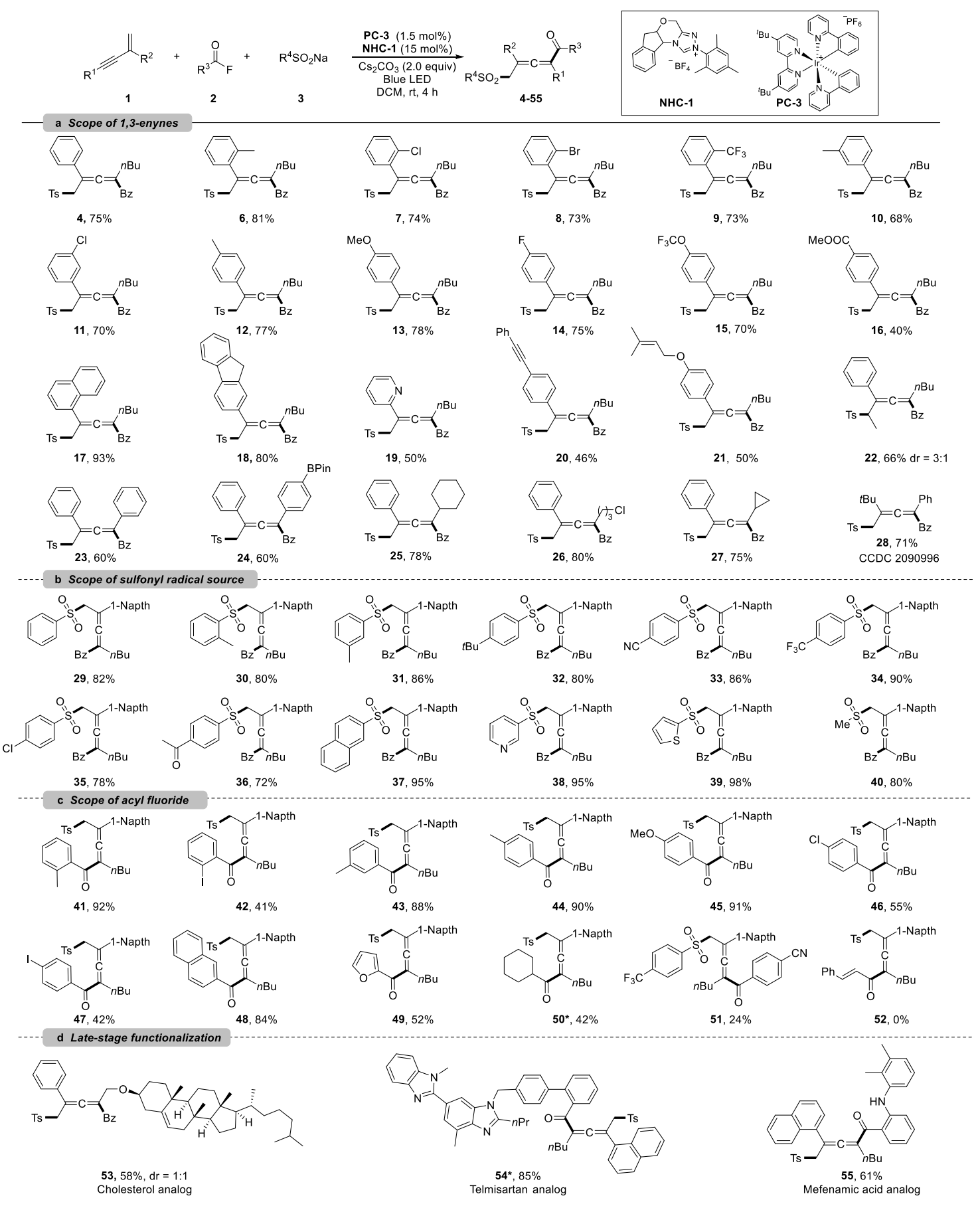

Fig. 3 Substrate scope for 1,4-sulfonylacylation of 1,3-enynes. a Scope of 1,3-enynes. b Scope of sulfonyl radical source. c Scope of acyl fluoride. d Late-stage functionalization. Reaction conditions: Unless otherwise noted, all the reactions were carried out with $1(0.2 \mathrm{mmol}), 2$ (0.4 mmol), 3 (0.4 mmol), NHC-1 (0.03 mmol), PC-3 (0.003 mmol) and $\mathrm{Cs}_{2} \mathrm{CO}_{3}(0.4 \mathrm{mmol})$ in DCM $(8 \mathrm{~mL})$ at $\mathrm{rt}$ under $\mathrm{N}_{2}$, irradiation with Blue LED for $4 \mathrm{~h}$. Isolated yield. "Reactions were carried out with in situ generated acyl fluoride; see the Supplementary Information for detailed reaction conditions. 
Synthetic applications. Large-scale synthesis and derivatization reactions were performed to showcase synthetic applications (Fig. 4a). Scale-up synthesis of $\mathbf{1 7}$ has been achieved at a $2.0 \mathrm{mmol}$ scale, and a comparable yield was obtained (Fig. 4a1). When employing PhLi as a base, the tetrasubstituted allenyl ketones 4 could isomerize to diene product 56 in $78 \%$ yield. 4 could undergo reduction of ketone unit with $\mathrm{NaBH}_{4}$. The allenyl ketone $\mathbf{4}$ could easily be transformed into conjugated viny selenyl ether $\mathbf{5 8}$ in $50 \%$ yield with excellent $\mathrm{Z} / \mathrm{E}$ selectivity. When treated with concentrated $\mathrm{H}_{2} \mathrm{SO}_{4}$, Nazarov cyclization product $\mathbf{5 9}$ was isolated in $86 \%$ yield.

Mechanism investigations. A series of control experiments were performed to unravel the reaction mechanism (Fig. 4b). Light, NHCs, and photoredox catalysis were indispensable for this 1,4-sulfonylacylation reaction (Fig. 4b1). When the radical scavenger 2,2,6,6-tetramethylpiperidine 1-oxyl (TEMPO) was added, the reaction was suppressed, and TEMPO-trapping product 60 was separated in 55\% yield (Fig. 4b2), thus suggesting the formation of ketyl radicals. Furthermore, a trace amount of 4,4'dimethyl-1,1'-biphenyl (62) was isolated under standard conditions, indicating the involvement of a sulfonyl radical. The intermediacy of acyl azoliums has been confirmed by coupling of acyl azolium ion 61 with 1,3-enynes 1a and sodium benzenesulfinate 3a in the absence of NHC (Fig. 4b3). The radical chain process could rule out based on light/dark experiments (Fig. S4, see Supplementary Information). Then Stern-Volmer quenching studies were conducted to clarify the plausible photoredox mechanism (Fig. 4c). 1,3-Enynes 1a and sodium benzenesulfinate 3a do not show a significant luminescence quenching effect to the excited state of the Ir*(III). In contrast, Ir*-complex was effectively quenched by acyl azolium ion $\mathbf{6 1}$, pointing to the oxidative quenching process. 


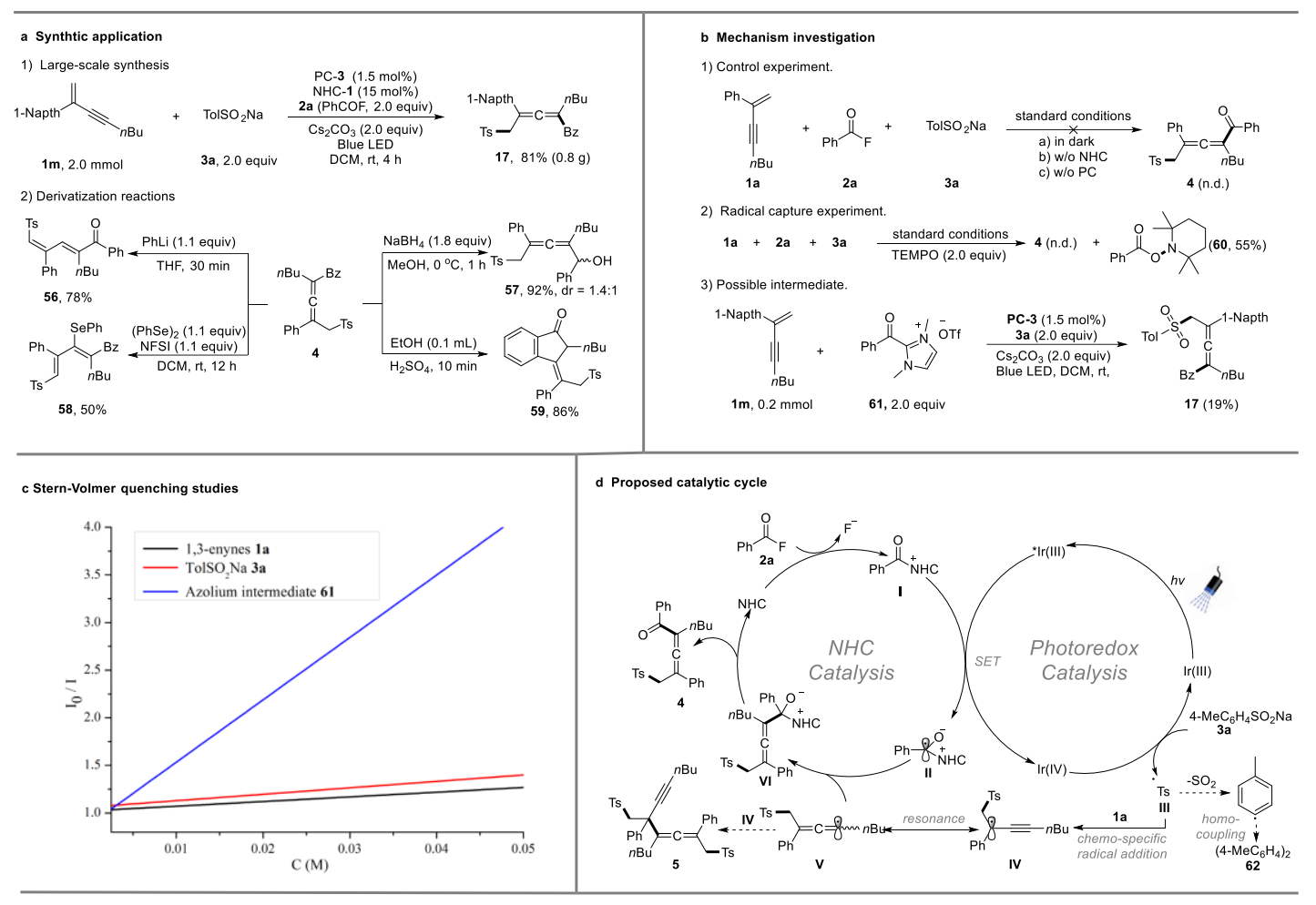

Fig. 4 Synthetic applications and mechanism investigations. a Synthetic applications. b Mechanism investigations. c Stern-Volmer quenching studies. d Proposed catalytic cycle.

Reaction mechanism. Based on series of experimental studies and previous reports, a plausible catalytic cycle for the 1,4-sulfonylacylation was proposed in Fig. 4d. Upon visible light irradiation, the excited state of $\left[\operatorname{Ir}(\mathrm{ppy})_{2}(\mathrm{dtbbpy})\right] \mathrm{PF}_{6}$ undergoes an oxidative quenching ${ }^{1}$ by acylazolium intermediate $\mathbf{I}$ to yield the $\mathrm{Ir}^{\mathrm{IV}}$-complex and ketyl radical II. Single-electron transfer between the $\mathrm{Ir}^{\mathrm{IV}}$-complex and aryl sulfinate provides an aryl sulfonyl radical III while regenerating the ground-state photocatalyst (Ir $\left.{ }^{\mathrm{III}}\right)$, closing the photoredox cycle. Sulfonyl radical then adds to the olefin unit of the 1,3enyne $\mathbf{1}$ delivering the propargyl radical $\mathbf{I V}$, which could undergo reversible resonance to generate trisubstituted allenyl radical $\mathbf{V} .{ }^{14}$ equently, chemo-specific radical/radical cross-coupling between the persistent ketyl radical II and transient allenyl radical $\mathbf{V}$ affords NHC-bound intermediate VI. The exclusive coupling selectivity might be regulated by the persistent radical effect ${ }^{1 \mathrm{~b}}$ as well as the steric exclusion of propargyl radical IV with ketyl radical II. Disintegrate of the VI to give rise to the final product 
4, while the NHCs was regenerated for the next NHCs cycle. Meanwhile, $\mathrm{SO}_{2}$ fragments of sulfonyl radical produced aryl radicals, which undergo homocoupling affording biaryl 62. Radical-radical cross-coupling of $\mathbf{V}$ and IV affords the by-product 5.

In summary, we have realized an efficient 1,4-sulfonylacylation of 1,3-enynes by merging photocatalysis with NHCs. This transformation provided a facile and direct entry for tetrasubstituted allenyl ketones under mild conditions with broad functional group tolerance and excellent chemo- and regioselectivity. Mechanistic studies indicated that the key step of the transformation is unprecedented allenyl and ketyl radical cross-coupling, proving a new avenue for NHCs catalyzed radical chemistry. Ketyl radical was formed from aroyl fluorides via the oxidative quenching process of excited photocatalysis. Further extension of this cross-coupling system to other destabilized transient radicals is ongoing in our laboratory.

\section{Methods}

General procedure for the synthesis of tetrasubstituted allenyl ketones. Into a nitrogenfilled glove box, a vial $(15.0 \mathrm{~mL})$ equipped with a magnetic stir bar was charged with NHC-1 (12.6 mg, $0.03 \mathrm{mmol}), \mathrm{Cs}_{2} \mathrm{CO}_{3}(130.3 \mathrm{mg}, 0.4 \mathrm{mmol})$, PC-3 (2.7 mg, 0.003 mmol), sulfinate $(71.3 \mathrm{mg}, 0.4 \mathrm{mmol})$ and DCM $(8.0 \mathrm{~mL})$. Then 1,3 -enynes $(0.2 \mathrm{mmol})$ and acyl fluorides $(0.4 \mathrm{mmol})$ were added. The vial was removed from the glove box, and then the reaction mixture was irradiated with Blue LED at room temperature for 4 hours. After the reaction finished that monitored by TLC, the reaction mixture was quenched by water. The mixture was extracted with EtOAc $(3 \times 5.0 \mathrm{~mL})$. The combined organic phases were dried over anhydrous $\mathrm{Na}_{2} \mathrm{SO}_{4}$, and the solvent was evaporated under vacuum. The residue was purified by flash column chromatography (petroleum ether/ethyl acetate $=10: 1$ ) to get the desired product.

\section{Data availability}


Supplementary information is available in the online version of the paper. Data supporting the findings of this work are available within this paper or its Supplementary Information and also from the corresponding author upon reasonable request.

\section{References}

[1] a) J. Xie, H. Jin, A. S. K. Hashmi, Chem. Soc. Rev. 2017, 46, 5193-5203; b) D. Leifert, A. Studer, Angew. Chem. Int. Ed. 2020, 59, 74-108; Angew. Chem. 2020, 132, 74-110; c) A. Bhunia, A. Studer, Chem 2021, 7, 1-41; d) J. D. Bell, J. A. Murphy, Chem. Soc. Rev. 2021, 50, 9540-9685; e) Y. Sohtome, K. Kanomata, M. Sodeoka, Bull. Chem. Soc. Jpn. 2021, 94, 1066-1079; f) Y. Yuan, J. Yanga, A. Lei, Chem. Soc. Rev. 2021, 50, 10058-10086.

[2] a) C. Chatgilialoglu, D. Crich, M. Komatsu, I. Ryu, Chem. Rev. 1999, 99, 1991-2069; b) A. Banerjee, Z. Lei, M. Ngai, Synthesis 2019, 303-333; c) Y. Liu, Y. Ouyang, H. Zheng, H. Liu, W. Wei Chem. Commun. 2021, 57, 6111-6120.

[3] a) D. Enders, O. Niemeier, A. Henseler, Chem. Rev. 2008, 107, 5606-5655; b) X. Bugaut, F. Glorius, Chem. Soc. Rev. 2012, 41, 3511-3522; c) M. N. Hopkinson, C. Richter, M. Schedler, F. Glorius, Nature 2014, 510, 485-496; d) J. Mahatthananchai, J. W. Bode, Acc. Chem. Res. 2014, 47, 696-707; e) R. S. Menon, A. T. Biju, V. Nair, Chem. Soc. Rev. 2015, 44, 5040-5052; f) D. M. Flanigan, F. Romanov-Michailidis, N. A. White, T. Rovis, Chem. Rev. 2015, 115, 9307-9387; g) C. Zhang, J. F. Hooper, D. W. Lupton, ACS Catal. 2017, 7, 2583-2596; h) X.-Y. Chen, Q. Liu, P. Chauhan, D. Enders, Angew. Chem. Int. Ed. 2018, 57, 3862-3873; Angew. Chem. 2018, 130, 39243935; i) K. J. R. Murauski, A. A. Jaworski, K. A. Scheidt, Chem. Soc. Rev. 2018, 47, 1773-1782; j) S. Mondal; S. R. Yetra, S. Mukherjee, A. T. Biju, Acc. Chem. Res. 2019, 52, 425-436; k) X. Chen, Z. Gao, S. Ye, Acc. Chem. Res. 2020, 53, 690-702.

[4] a) I. Nakanishi, S. Itoh, T. Suenobu, S. Fukuzumi, Chem. Commun. 1997, 1927-1928; b) J. K. Mahoney, D. Martin, C. E. Moore, A. L. Rheingold, G. Bertrand, J. Am. Chem. Soc. 2013, 135, 18766-18769; c) V. Regnier, E. A. Romero, F. Molton, R. Jazzar, G. Bertrand, D. Martin, J. Am. Chem. Soc. 2019, 141, 1109-1117.

[5] a) K. Zhao, D. Enders, Angew. Chem. Int. Ed. 2017, 56, 3754-3756; Angew. Chem. 2017, 129, 3808-3810; b) R. Song, Y. R. Chi, Angew. Chem. Int. Ed. 2019, 58, 8628-8630; Angew. Chem. 2019, 
131, 8720-8722; c) T. Ishii, K. Nagao, H. Ohmiya, Chem. Sci. 2020, 11, 5630-5636; d) Q. Liu, X.Y. Chen, Org. Chem. Front. 2020, 7, 2082-2087; e) H. Ohmiya, ACS Catal. 2020, 10, 6862-6869; f) K.-Q. Chen, H. Sheng, Q. Liu, P.-L. Shao, X.-Y. Chen, Sci. China Chem. 2021, 64, 7-16; g) Q.Z. Li, R. Zeng, B. Han, J.-L. Li, Chem. Eur. J. 2021, 27, 3238-3250.

[6] a) J. Guin, S. D. Sarkar, S. Grimme, A. Studer, Angew. Chem. Int. Ed. 2008, 47, 8727-8730; b) J. Zhao, C. Mück-Lichtenfeld, A. Studer, Adv. Synth. Catal. 2013, 355, 1098-1106; c) Q.-Y. Meng, N. Döben, A. Studer, Angew. Chem. Int. Ed. 2020, 59, 19956 -19960; Angew. Chem. 2020, 132, 20129 -20134; d) K. Liu, A. Studer, J. Am. Chem. Soc. 2021, 143, 4903-4909; e) Q.-Y. Meng, L. Lezius, A. Studer, Nat. Commun. 2021, 12, 2068; f) Z. Zuo, C. G. Daniliuc, A. Studer, Angew. Chem. Int. Ed. 2021, DOI: 10.1002/anie.202110304.

[7] a) T. Ishii, Y. Kakeno, K. Nagao, H. Ohmiya, J. Am. Chem. Soc. 2019, 141, 3854-3858; b) Y. Kakeno; M. Kusakabe; K. Nagao; H. Ohmiya, ACS Catal. 2020, 10, 8524-8529.

[8] I. Kim, H. Im, H. Lee, S. Hong, Chem. Sci. 2020, 11, 3192-3197.

[9] a) A.V. Davies, K.P. Fitzpatrick, R.C. Betori, K.A. Scheidt, Angew. Chem. Int. Ed. 2020, 59, 9143-9148; Angew. Chem. 2020, 132, 9228-9233; b) A. A. Bayly, B. R. McDonald, M. Mrksich, K. A. Scheidt, Proc. Natl. Acad. Sci. U. S. A. 2020, 117, 13261-13266; c) A. V. Bay, K. P. Fitzpatrick, G. A. González-Montiel, A. O. Farah, P. H. Cheong, K. A. Scheidt, Angew. Chem. Int. Ed. 2021, 60, 17925-17931; Angew. Chem. 2021, 133, 18069-18075; d) S.-C. Ren, W.-X. Lv, X. Yang, J.-L. Yan, J. Xu, F.-X. Wang, L. Hao, H. Chai, Z. Jin, Y. R. Chi, ACS Catal. 2021, 11, 2925-2934.

[10] a) T. Ishii, K. Ota, K. Nagao, H. Ohmiya, J. Am. Chem. Soc. 2019, 141, 14073-14077; b) K. Ota, K. Nagao, H. Ohmiya, Org. Lett. 2020, 22, 3922-3925; c) Y. Matsuki, N. Ohnishi, Y. Kakeno, S. Takemoto, T. Ishii, K. Nagao, H. Ohmiya, Nat. Commun. 2021, 12, 3848; d) H.-B. Yang, Z.-H. Wang, J.-M. Li, C. Wu, Chem. Commun. 2020, 56, 3801-3804; e) J.-L. Li, Y.-Q. Liu, W.-L. Zou, R. Zeng, X. Zhang, Y. Liu, B. Han, Y. He, H.-J. Leng, Q.-Z. Li, Angew. Chem. Int. Ed. 2020, 59, $1863-$ 1870; Angew. Chem. 2020, 132, 1879-1886; f) B. Zhang, Q. Peng, D. Guo, J. Wang, Org. Lett. 2020, 22, 443-447; g) Y. Sato, Y. Goto, K. Nakamura, Y. Miyamoto, Y. Sumida, H. Ohmiya, ACS Catal. 2021, 11, 12886-12892. 
[11] a) A. Mavroskoufis, M. Jakob, M. N. Hopkinson, ChemPhotoChem. 2020, 4, 5147-5153; b) J. Liu, X.-N. Xing, J.-H. Huang, L.-Q. Lu, W.-J. Xiao, Chem. Sci. 2020, 11, 10605-10613.

[12] a) D. A. DiRocco, T. Rovis, J. Am. Chem. Soc. 2012, 134, 8094-8097; b) L. Dai, Z.-H. Xia, Y.Y. Gao, Z.-H. Gao, S. Ye, Angew. Chem. Int. Ed. 2019, 58, 18124-18130; Angew. Chem. 2019, 131, 18292-18298; c) A. Mavroskoufis, K. Rajes, P. Golz, A. Agrawal, V. Ruß, J. P. Götze, M. N. Hopkinson, Angew. Chem. Int. Ed. 2020, 59, 3190-3194; Angew. Chem. 2020, 132, 3216-3220.

[13] L. Fu, S. Greßies, P. Chen, G. Liu, Chin. J. Chem. 2020, 38, 91-100.

[14] a) F. Wang, D. Wang, Y. Zhou, L. Liang, R. Lu, P. Chen, Z. Lin, G. Liu, Angew. Chem. Int. Ed. 2018, 57, 7140-7145; Angew. Chem. 2018, 130, 7258-7263; b) X. Zhu, W. Deng, M.-F. Chiou, C. Ye, W. Jian, Y. Zeng, Y. Jiao, L. Ge, Y. Li, X. Zhang, H. Bao, J. Am. Chem. Soc. 2019, 141, 548559; c) Y. Zeng, M.-F. Chiou, X. Zhu, J. Cao, D. Lv, W. Jian, Y. Li, X. Zhang, H. Bao, J. Am. Chem. Soc. 2020, 142, 18014-18021; d) Y. Chen, J. Wang Y. Lu, Chem. Sci. 2021, 12, 11316-11321; e) J. Terao, F. Bando, N. Kambe, Chem. Commun. 2009, 7336-7338; f) K.-F. Zhang, K.-J. Bian, C. Li, J. Sheng, Y. Li, X.-S. Wang, Angew. Chem. Int. Ed. 2019, 58, 5069-5074; Angew. Chem. 2019, 131, 5123-5128; g) C. Ye, Y. Li, X, Zhu, S. Hu, D. Yuan, H. Bao, Chem. Sci. 2019, 10, 3632-3636; h) Y. Chen, K. Zhu, Q. Huang, Y. Lu, Chem. Sci. 2021, DOI: 10.1039/D1SC04320J; i) Y. Song, S. Song, X. Duan, X. Wu, F. Jiang, Y. Zhang, J. Fan, X. Huang, C. Fu, S. Ma, Chem. Commun. 2019, 55, 11774-11777; j) X.-Y. Dong, T.-Y. Zhan, S.-P. Jiang, X.-D. Liu, L. Ye, Z.-L. Li, Q.-S. Gu, X.-Y. Liu, Angew. Chem. Int. Ed. 2021, 60, 2160-2164; Angew. Chem. 2021, 133, 2188-2192; k) H. Shen, H. Xiao, L. Zhu, C. Li, Synlett 2020, 31, A-D; 1) C. Alameda-Angulo, B. Quiclet-Sire, S. Z. Zard, Tetrahedron Letters 2006, 47, 913-916.

[15] A. Hoffmann-Roder, N. Krause, Angew. Chem. Int. Ed. 2004, 43, 1196-1216.

[16] a) A. S. Dudnik, V. Gevorgyan, Angew. Chem. Int. Ed. 2007, 46, 5195-5197; b) M. Miao, J. Cao, X. Huang, Luling Wu, J. Org. Chem. 2013, 78, 5999-6007; c) C. Xue, X. Huang, S. Wu, J. Zhou, J. Dai, C. Fu, S. Ma Chem. Commun. 2015, 51, 17112-17115; d) M. Miao, Y. Luo, H. Xu, Z. Chen, J. Xu, H. Ren, Org. Lett. 2016, 18, 4292-4295; e) M. Miao, H. Xu, Y. Luo, M. Jin, Z. Chen, J. Xu, H. Ren, Org. Chem. Front. 2017, 4, 1824-1828; f) J. Teske, B. Plietker, Org. Lett. 2018, 20 , $2257-2260$. 
[17] a) H. Zhang, W. Pu, T. Xiong, Y. Li, X. Zhou, K. Sun, Q. Liu, Q. Zhang, Angew. Chem. Int. Ed. 2013, 52, 2529-2533; Angew. Chem. 2013,125, 2589-2593; b) H. Zhang, Y. Song, J. Zhao, J. Zhang, Q. Zhang, Angew. Chem. Int. Ed. 2014, 53, 11079-11083; Angew. Chem. 2014, 126, 11259-11263;

c) G. Zhang, T. Xiong, Z. Wang, G. Xu, X. Wang, Q. Zhang, Angew. Chem. Int. Ed. 2015, 54, 1264912653; Angew. Chem. 2015, 127, 12840-12844; d) G. Zheng, Y. Li, J. Han, T. Xiong, Q. Zhang, Nat. Commun. 2015, 6, 7011; e) J. Sun, G. Zheng, T. Xiong, Q. Zhang, J. Zhao, Y. Li, Q. Zhang. ACS Catal. 2016, 6, 3674-3678; f) S. Yang, L. Wang, H. Zhang, C. Liu, L. Zhang, X. Wang, G. Zhang, Y. Li, Q. Zhang, ACS Catal. 2019, 9, 716-721; g) T. Qin, G. Lv, Q. Meng, G. Zhang, T. Xiong, Q. Zhang, Angew. Chem. Int. Ed. 2021, DOI: 10.1002/anie.202110178.

[18] CCDC 2090996 (28) contain the supplementary crystallographic data for this paper. This data can be obtained free of charge from The Cambridge Crystallographic Data Centre.

[19] a) J. Xuan, W. Xiao, Angew. Chem. Int. Ed. 2012, 51, 6828-6838; Angew. Chem. 2012, 124, 6934-6944; b) C. K. Prier, D. A. Rankic, D. W. C. MacMillan, Chem. Rev. 2013, 113, 5322-5363; c) J. D. Slinker, A. A. Gorodetsky, M. S. Lowry, J. Wang, S. Parker, R. Rohl, S. Bernhard, G. G. Malliaras, J. Am. Chem. Soc. 2004, 126, 2763-2767.

\section{Acknowledgements}

We acknowledge the NSFC (21831002, and 22001157), Ten Thousand Talents Program, the Fundamental Research Funds for the Central Universities (2412021QD007), and the Natural Science Foundation of Shaanxi Province (2020JQ-404) for generous financial support.

\section{Author contributions}

G. Z. and Q. Z. conceived and designed the project. L. W., R. M and J. S. performed the experiments and analyzed the data. G. Z. and Q. Z. wrote the manuscript.

\section{Competing interests}

The authors declare no competing interests.

\section{Additional information}

Supplementary information The online version contains supplementary material available at Correspondence and requests for materials should be addressed to Guangfan Zheng or Qian Zhang. 